\title{
EGFR mutations as a prognostic and predictive marker in non-small-cell lung cancer
}

\author{
This article was published in the following Dove Press journal: \\ Drug Design, Development and Therapy \\ 26 September 2014 \\ Number of times this article has been viewed
}

\author{
Shu Fang' \\ Zhehai Wang ${ }^{2}$ \\ 'School of Medicine and Life Sciences, \\ University of Jinan-Shandong Academy \\ of Medical Sciences, Shandong \\ Cancer Hospital, Jinan, Shandong \\ Province, People's Republic of China; \\ ${ }^{2}$ Department of Oncology, Shandong \\ Cancer Hospital, Jinan, Shandong \\ Province, People's Republic of China
}

\begin{abstract}
Non-small-cell lung cancer (NSCLC) has entered the age of individual treatment, and increasing point mutations of specific oncogenes and rearrangement of some chromosomes are biomarkers used to predict the therapeutic effect of targeted therapy. At present, there is a consensus among clinicians that epidermal growth factor receptor (EGFR) tyrosine kinase inhibitors (TKIs) have shown favorable efficacy in NSCLC patients with EGFR mutation, and some relevant research has suggested that the presence of $E G F R$ mutations is a favorable prognostic marker. However, the association of EGFR mutation status with the responsiveness to conventional chemotherapy agents and survival in NSCLC patients is still unclear. This review provides an overview of and assesses the role of $E G F R$ as a prognostic marker for postoperative patients and as a predictive marker for response to cytotoxic chemotherapy. In addition, we review the comparison of response to chemotherapy between EGFR mutations in exon 19 and in exon 21 and the predictive role of p.T790M mutation.
\end{abstract}

Keywords: epidermal growth factor receptor, prediction, prognosis

\section{Introduction}

At present, lung cancer is the leading cause of carcinoma-related death in industrialized countries, ${ }^{1}$ and $75 \%-80 \%$ of primary lung cancers are non-small-cell lung cancer (NSCLC). ${ }^{2}$ Although surgical operation is the most effective therapy for NSCLC, many cases with advanced stage are unresectable, ${ }^{3-5}$ and, for these patients, the preferred treatment is chemotherapy. Even though NSCLC patients have a chance to receive complete resection, they also face the risk of recurrence. ${ }^{6}$ Therefore, whether certain biomarkers could exist as predictive factors of the chemotherapy and be used for decisions about treatment options is extremely important in clinical decision-making.

Epidermal growth factor receptor $(E G F R)$ is a member of the ErbB receptor tyrosine kinase (TK) family and has an essential action in the development and progression of NSCLC. ${ }^{7-9}$ It has been reported that the signaling pathways of EGFR could influence angiogenesis, activation and regulation of cellular proliferation, and the epithelial-mesenchymal transition (Figure 1). ${ }^{10-13}$ The gene with the most frequent mutations in NSCLC is EGFR. The most common EGFR mutations reported are deletions in exon 19 and the p.L858R point mutation in exon $21(85 \%-90 \%) .{ }^{14,15}$ It has been reported that EGFR mutations usually occur in a subset of NSCLC patients with the following features: nonsmoker, female, East Asian, adenocarcinoma with bronchioloalveolar carcinoma, and well- or moderately differentiated tumor cells. ${ }^{16-18}$ During the past decade, some research demonstrated that EGFR TK inhibitor (EGFR-TKI) sensitivity was influenced by the presence of EGFR mutations and increased EGFR copy numbers. ${ }^{19-25}$ Some Phase III trials also revealed that, compared with those treated with erlotinib or gefitinib, the EGFR-mutated NSCLC
Correspondence: Zhehai Wang Department of Oncology, Shandong Cancer Hospital, No 440 Jiyan Road, Jinan, Shandong 250I 17, People's Republic of China

Tel/fax +86 53I 6762633 I

Email wzhai8778@sina.com
Drug Design, Development and Therapy 2014:8 I595-16II

1595

Dovepress

http://dx.doi.org/10.2147/DDDT.S69690 (c) (i) (5) 2014 Fang and Wang. This work is published by Dove Medical Press Limited, and licensed under Creative Commons Attribution - Non Commercial (unported, v3.0) BV NC License. The full terms of the License are available at http:///creativecommons.org/licenses/by-nd/3.0/. Non-commercial uses of the work are permitted without any further
permission from Dove Medical Press Limited, provided the work is properly attributed. Permissions beyond the scope of the License are administered by Dove Medical Press Limited. Information on permission from Dove Medical Press Limited, provided the work is properly attributed. P
how to request permission may be found at: http://www.dovepress com/permissions 


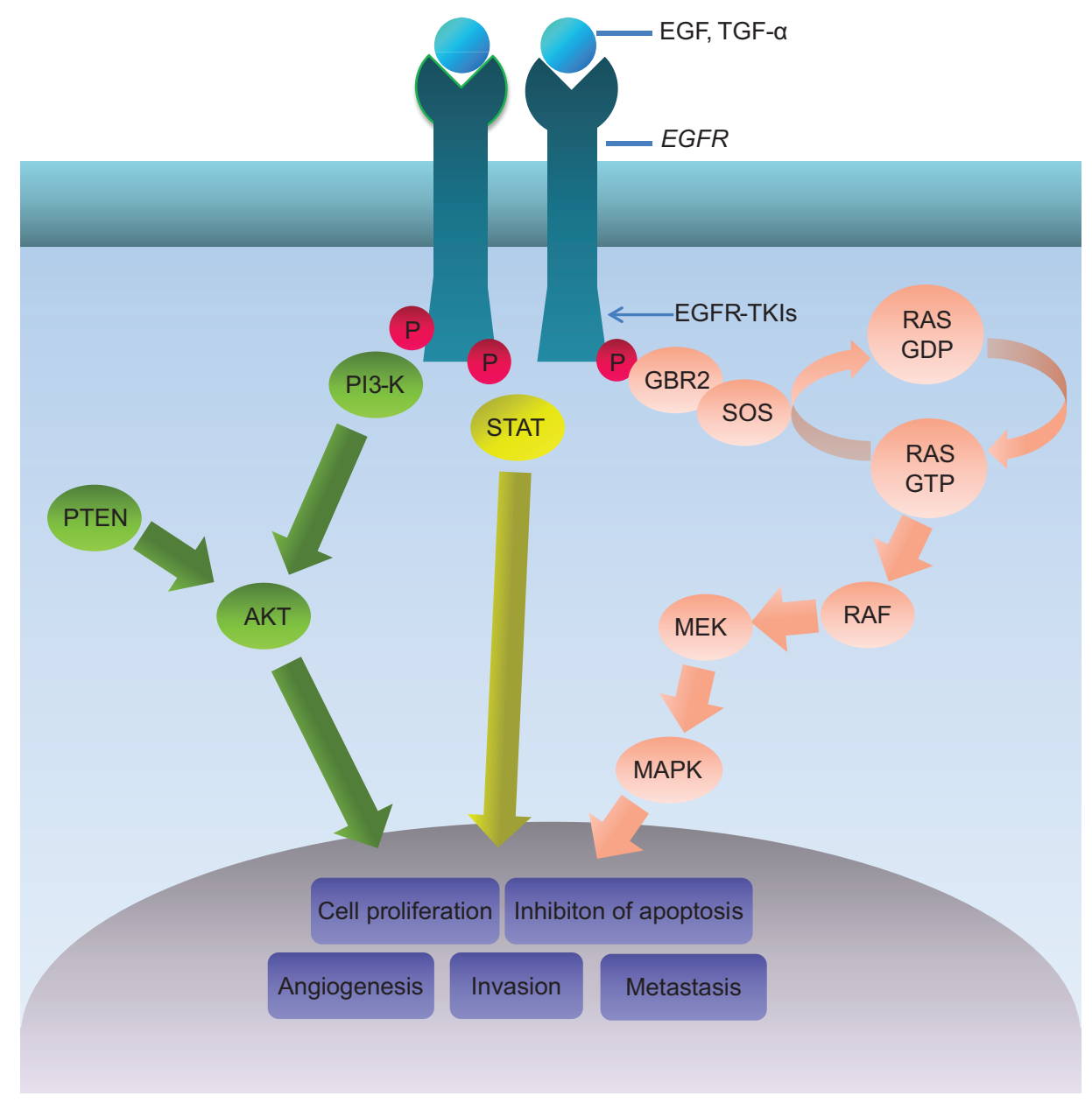

Figure I EGFR signaling pathway.

Abbreviation: EGFR, epidermal growth factor receptor; EGFR-TKIs, epidermal growth factor receptor tyrosine kinase inhibitors; P, phosphorylate.

patients who were treated with normal chemotherapy had poorer clinical outcomes. ${ }^{26,27}$ Currently, relevant research results suggest that the mutant status of EGFR can likely be a predicting factor for the response to cytotoxic chemotherapy and prognosis of advanced NSCLC patients; however, this issue remains debatable.

In this review, we aim to summarize the role of $E G F R$ as a prognostic marker for postoperative patients and as a predictive marker for response to cytotoxic chemotherapy. In addition, we review the comparison of response to chemotherapy between EGFR mutations in exon 19 and in exon 21 and the predictive role of p.T790M mutation.

\section{Materials and methods Search strategy}

PubMed was searched using the following keywords: "nonsmall-cell lung cancer", "EGFR", “erlotinib", "gefitinib", "afatinib", "chemotherapy", "p.T790M", "mutation", "predictive", and "prognostic". The online proceedings of the
American Society of Clinical Oncology annual meeting and the World Conferences on Lung Cancer were searched for publications from 2004 to 2014 using the same keywords. In addition, the reference lists of relevant articles were searched. Search results were limited to articles in English.

\section{Trial identification criteria}

Clinical randomized trials, prospective cohort studies, and retrospective studies were included. Studies that evaluated the relationship between $E G F R$ mutations and the outcomes of NSCLC patients were included. In addition, the included studies had to satisfy the following criteria: patients had a pathological diagnosis of NSCLC; patients had a clear EGFR mutation status; and at least one outcome regarding response rate $(\mathrm{RR})$ or survival time was reported.

\section{Data extraction}

Data recorded from each single study included authors' names, publication year, study design, objectives, sample 
size, EGFR mutation rate, and effects on patient outcomes (RR, survival, recurrence). Two reviewers independently conducted a data extraction from the original reports. Disagreements were resolved by consensus or by arbitration of a third reviewer.

\section{Outcome definition}

Based on the Response Evaluation Criteria in Solid Tumors (RECIST) 1.1 guidelines, ${ }^{28}$ complete response and partial response (PR) were defined as the RR, and complete response, $\mathrm{PR}$, and stable disease were defined as the disease control rate (DCR). Disease-free survival (DFS) was defined as the time from the date of surgery to proven recurrence or death. Progression-free survival (PFS) was defined as the time from the date of starting the therapy to disease progression or death. Overall survival (OS) was defined as the time from the date of surgery or starting the therapy to death or last follow-up. Post-recurrence survival was defined as the time from the date of recurrence to death or last follow-up. Time to treatment failure (TTF) was defined as the time from the date of starting the treatment to disease progression or death. Two-sided $P$-values $<0.05$ were considered statistically significant.

\section{EGFR mutations as a prognostic marker for postoperative patients with NSCLC}

Recently, the predictive factors of postoperative prognosis in NSCLC patients have received much attention. Although outcomes after curative resection are improving, long-term survival time is still poor, resulting from a high rate of relapse. ${ }^{29-31}$ Several studies have shown that the 5-year OS rates remained at 24\%-58\% after complete resection in stage IA-IIIA NSCLC patients. ${ }^{32-34}$ Therefore, clarifying the role of EGFR mutation status in predicting the outcome of NSCLC patients with resection is essential clinical work.

The prognostic value of EGFR mutations in resected NSCLC remains debatable (Table 1). Several studies have indicated that the presence of EGFR mutations meant longer survival times for patients with NSCLC who received surgical treatment. In a study by Lee et $\mathrm{al}^{35} 117$ patients with surgically resected pulmonary adenocarcinoma were reviewed, including 53 patients with $E G F R$ mutations and 64 patients with wild-type $E G F R$. The results revealed that $E G F R$ mutations were significantly associated with longer DFS (34.4 versus 20.1 months, $P=0.003$ ), but $E G F R$ mutations had no correlation with OS $(P=0.39)$. In multivariate analysis of DFS, wild-type $E G F R$ was associated with a higher risk of recurrence after curative resection (hazard ratio [HR] 1.42, 95\% confidence interval [CI]: 1.10-2.41,
$P=0.04)$. Although there was not a statistically significant difference, isolated brain metastasis as the first recurrence was found more frequently in patients with $E G F R$ mutations (24\% versus 9\%, $P=0.15$ ).

In a recent study performed by Jeon et $\mathrm{al}^{36} 138$ patients who underwent surgical resection with adenocarcinoma and had postoperative recurrence were included in the research. $E G F R$ mutation was an independent prognostic factor for post-recurrence survival (HR 0.552, $P=0.013$ ) and survival time (HR 0.552, 95\% CI: 0.345-0.882, $P=0.013$ ) in multivariable analysis.

Similarly, Sasaki et $\mathrm{al}^{37}$ analyzed the information of 95 NSCLC patients who underwent surgical resection. Compared with those with wild-type $E G F R$, they found that the patients with $E G F R$ mutations had a longer survival time $(P=0.0143)$. However, a multivariate analysis did not prove that $E G F R$ mutation was the significant factor $(P=0.1824)$. Kosaka et $\mathrm{al}^{38}$ analyzed 397 Japanese patients who were treated with curative pulmonary resection with lung adenocarcinoma. Although the results of multivariate analysis showed EGFR mutations were not independent factors related to the prognosis ( $P=0.3225)$, the authors found that the $E G F R$ mutation patients had a longer survival time than those with wild-type $E G F R$.

A study by D'Angelo et al ${ }^{39}$ enrolled the largest cohort ever reported $(n=1,118)$ in an investigation of whether EGFR mutations could be used to predict the prognosis of postoperative patients with NSCLC EGFR mutation was detected in $222(19.9 \%)$ patients. The results showed that patients with EGFR mutations had a lower risk of death (HR 0.51, $P<0.001)$ and a longer OS (HR 0.51, 95\% CI: 0.34-0.76, $P<0.001)$ than those with $E G F R$ wild-type. They also found that a survival time of more than 10 years $(n=286)$ only occurred in patients with EGFR mutation in lung cancer.

However, several studies revealed that EGFR mutation status had no prognostic value in patients who underwent surgical resection with adenocarcinomas. A total of 131 patients with completely resected lung adenocarcinoma whose pathologic stage was IA-IIIA were included in a study by Liu et $\mathrm{al}^{40}$ in which no significant correlation was observed between median DFS (36.6 versus 25.7 months, $P=0.533$ ), $\operatorname{OS}(P=0.564)$, the recurrence rate, and $E G F R$ mutation status. The results of multivariate analysis revealed that the lymph node $(\mathrm{N})$ status $(P=0.037)$ and distant metastasis $(P<0.001)$ were significant predictive factors for OS.

Kobayashi et $\mathrm{al}^{41}$ performed a retrospective study to evaluate the factors related to poor outcomes of stage IA lung adenocarcinoma patients with surgical resection; 127 patients 


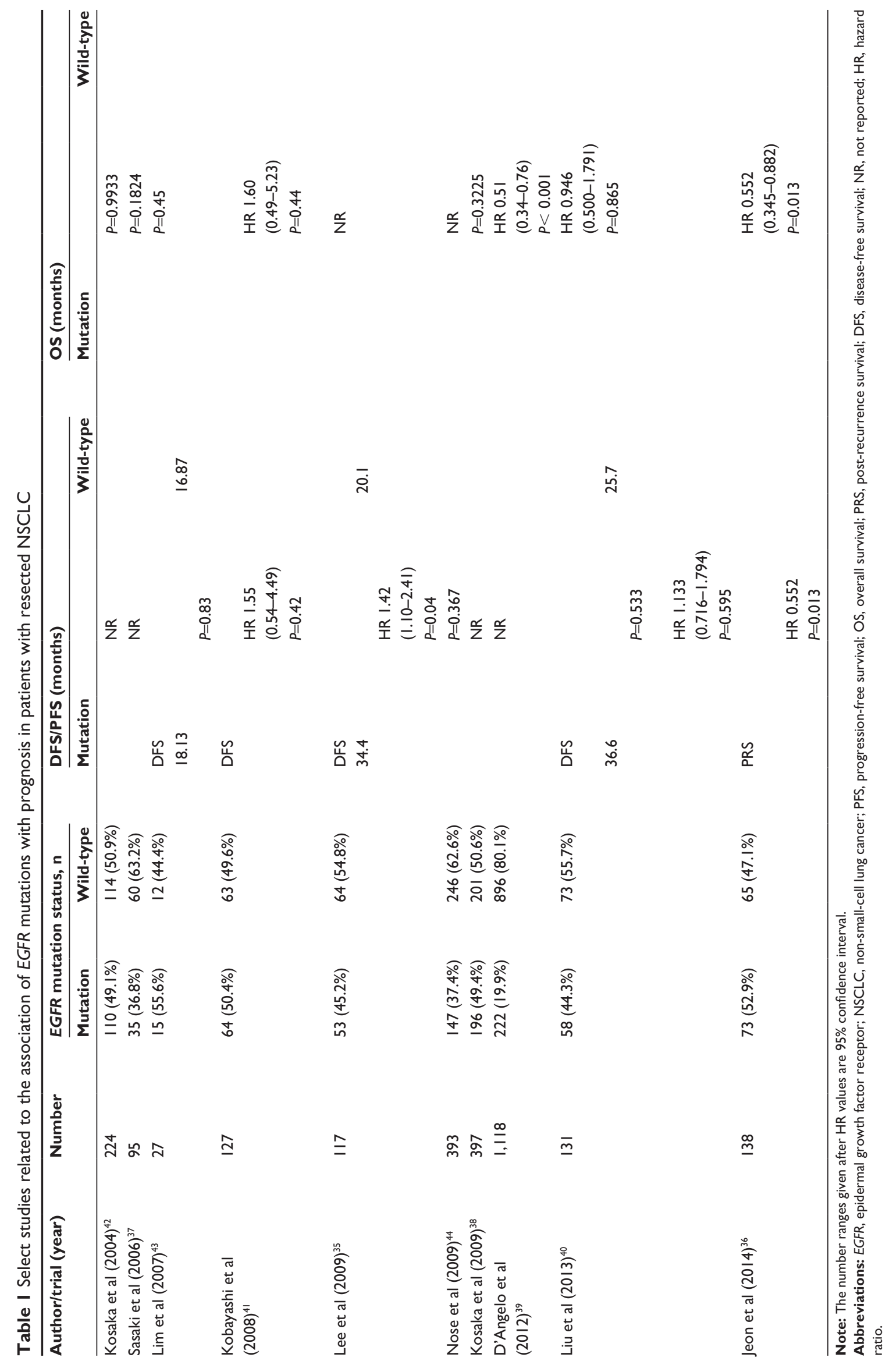


were included in the study. The results indicated that there was no correlation between EGFR mutations and recurrence (HR 1.42 , 95\% CI: $0.38-5.29, P=0.60$ ) or survival (HR 1.60, 95\% CI: $0.49-5.32, P=0.44$ ) in patients with lung adenocarcinoma $20 \mathrm{~mm}$ or less. These results were consistent with those of a study by Kosaka et $\mathrm{al}^{42}$ who revealed that EGFR mutations did not influence the prognosis of patients with adenocarcinoma who underwent surgical resection $(P=0.9933)$.

A total of 27 patients with resected lung adenocarcinomas were enrolled in a study performed by Lim et al. ${ }^{43}$ EGFR mutations were detected in 15 patients $(55.6 \%)$. The results showed there was no significant difference in DFS (16.87 versus 18.13 months, $P=0.83)$ and $O S(P=0.45)$ between $E G F R$ mutation patients and those with wild-type EGFR. Similarly, among 393 Japanese patients who underwent a complete resection of adenocarcinoma in a study by Nose et $\mathrm{al}^{44}$ there was no significant DFS difference between $E G F R$ mutation patients and patients with wild-type $E G F R(P=0.367)$.

At present, $E G F R$ and $K R A S$ mutations are known for having biologic relevance. Marks et $\mathrm{al}^{45}$ analyzed the clinical outcomes data of 296 patients with stage I-III lung adenocarcinoma who underwent resection and compared outcomes between patients with $E G F R$ mutation and $K R A S$ mutation. The results revealed that patients with $E G F R$ mutation had a higher 3-year OS than patients with $K R A S$ mutant tumors (90\% versus $66 \%$ ) and suggested the NSCLC patients with EGFR mutation might have a more favorable prognosis.

Based on the previous studies, ${ }^{35-45}$ the prognostic role of EGFR mutations was not clear in patients with resected NSCLC. Although several studies did not report a significant difference in survival time between patients with and without $E G F R$ mutations who underwent a resection of NSCLC, $40-44$ we believe that the presence of EGFR mutations is related to improved prognosis because of the better clinicopathologic characteristics. However, we cannot obtain a certain conclusion on this issue because of different postoperative treatments and the small population of patients in previous research. Therefore, further prospective studies are needed to investigate the prognostic value of $E G F R$ mutations after surgical resection.

\section{EGFR mutations as a predictive marker for response to cytotoxic chemotherapy in NSCLC}

First-line treatment

Platinum-based doublet chemotherapy is the standard firstline therapy for advanced-stage NSCLC. ${ }^{46-48}$ Currently, although chemotherapy regimens are continuously updated, the curative effect of chemotherapy for NSCLC has reached a plateau. ${ }^{49,50}$ There is an urgent need to develop individualized treatments for NSCLC patients. Some research has indicated that EGFR mutations may be used as a predictive marker for the response to conventional cytotoxic chemotherapies (Table 2). ${ }^{51-69}$ Although the results of these studies differed, they may suggest that there is a certain correlation between EGFR mutations and the response to cytotoxic agents.

The IRESSA Pan-Asia Study (IPASS) ${ }^{51,52}$ was a randomized Phase III study that included 1,217 patients with advanced lung adenocarcinoma from 87 clinical research centers of nine Asian countries. The purpose of the study was to compare the efficiency of gefitinib and carboplatin/paclitaxel. The researchers found that the RR was higher in EGFR mutation patients compared with wild-type EGFR cases $(47.3 \%$ versus $23.5 \%$ ). The research revealed that EGFR mutations may be a favorable predictive factor for the response to cytotoxic chemotherapy in NSCLC patients. However, the results of another Phase III trial indicated that patients with $E G F R$ mutations had a similar RR to EGFR wild-type patients after receiving chemotherapy. ${ }^{53}$ In the first-line randomized Phase III Iressa NSCLC Trial Assessing Combination Treatment (INTACT) trials, Bell et $\mathrm{al}^{54}$ found that EGFR mutationpositive patients treated only with chemotherapy had a better OS (19.4 versus 9.2 months) than those with wild-type mutations, but there was no significant difference in RR between the two groups $(40.0 \%$ versus $39.0 \%)$.

Similar results were found in other studies. The study by Eberhard et $\mathrm{al}^{55}$ indicated that the presence of EGFR mutations was associated with higher RR (38\% versus $23 \%$, $P=0.01)$ and longer time to progression despite a therapeutic regimen ( 8.0 versus 5.0 months, $P<0.001$ ). The study by Hotta et $\mathrm{al}^{56}$ demonstrated that EGFR mutations were significantly correlated with a better PFS (HR 0.422, $P=0.0422$ ) and OS (HR 0.263, $P=0.0074$ ) in 54 Japanese patients with advanced NSCLC receiving first-line cytotoxic regimens, whereas they observed that the objective response was not affected by the presence of $E G F R$ mutations ( $P=0.6842)$. However, the correlation of $E G F R$ mutation with PFS was not found in the patients who received chemotherapy after the failure of the first-line gefitinib $(P=0.0764)$.

Kalikaki et $\mathrm{al}^{57}$ evaluated the clinical outcome of 162 patients with advanced NSCLC who received first-line chemotherapy and divided patients with EGFR mutations into two groups, which included those who had classical activating mutations (Del19, p.L858R, p.G719D, and p.E746V) and those who carried other mutations of unknown effect. The data indicated that patients with 


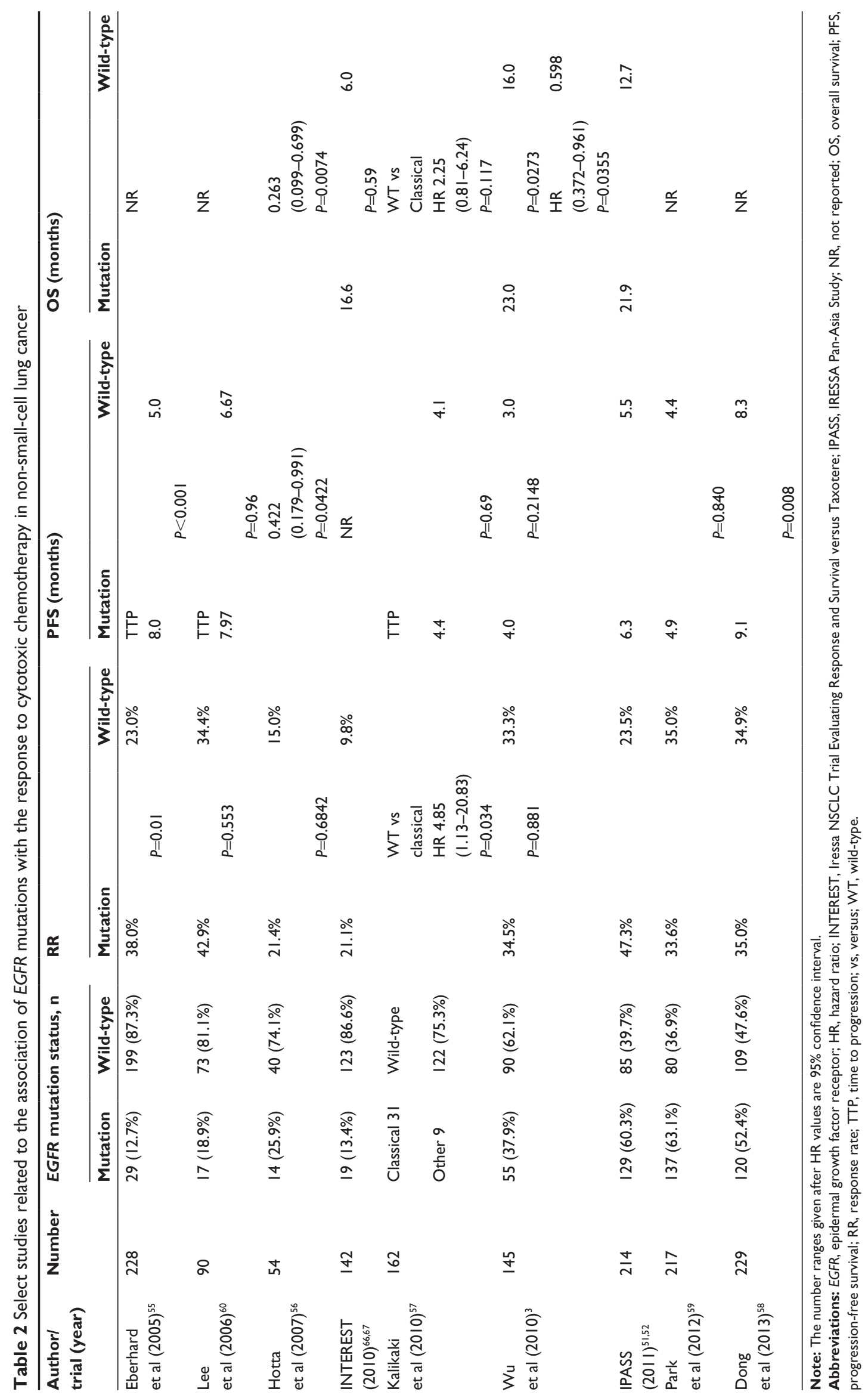


classical EGFR mutations had a higher effectiveness of first-line chemotherapy than those with wild-type $E G F R$ mutations patients $(55.6 \%$ versus $21.8 \%, P=0.023)$, while, among patients treated with platinum-based regimens as the first-line treatment, OS was significantly longer in patients with classical $E G F R$ mutations than in those without mutations (35.9 versus 15.3 months, $P=0.043$ ). In multivariate analysis, the presence of $E G F R$ mutations was an independent factor associated with response to first-line chemotherapy (HR 4.85; 95\% CI: 1.13-20.83; $P=0.034$ ).

$\mathrm{Wu}$ et $\mathrm{al}^{3}$ retrospectively analyzed 145 cases of stages IIIB and IV NSCLC patients who received first-line chemotherapy. The results indicated that no statistical difference in RR to the first-line chemotherapy between EGFR mutation carriers and wild-type $E G F R$ patients was observed (34.5\% versus $33.3 \%, P=0.881$ ). The mutated $E G F R$ patients had a longer median survival time and higher 1- and 2-year survival rates than those with wild-type $E G F R$ (23 versus 16 months, $86.38 \%$ versus $62.64 \%$, and $38.78 \%$ versus $27.16 \%$, respectively, $P=0.0273$ ). Among stage IV patients, those with $E G F R$ mutations had a longer PFS than wild-type EGFR patients ( 5 versus 3 months, $P=0.040$ ). Multivariate analysis demonstrated that the efficiency of the first-line chemotherapy and $E G F R$ mutation status were independent prognostic factors (HR 0.461, $P=0.0042$ and HR 0.598, $P=0.0335$, respectively) for advanced NSCLC patients. The results of the study ${ }^{3}$ suggested that $E G F R$ mutations had a relationship with survival time rather than with the response to first-line chemotherapy in patients with advanced NSCLC.

There are some related studies which indicate that certain therapies could demonstrate higher efficiency in NSCLC patients with EGFR mutation. Dong et $\mathrm{al}^{58}$ reviewed 229 patients with advanced NSCLC who received platinumbased doublet chemotherapy as the first-line treatment. Although the RRs were not influenced by EGFR mutation status, there was significant difference in the PFS between patients with wild-type $E G F R$ and $E G F R$ mutations (8.3 versus 9.1 months, $P=0.008)$. In 120 patients with $E G F R$ mutation, DCR was higher in patients treated with docetaxel when compared with patients treated with gemcitabine $(88.6 \%$ versus $67.5 \%, P=0.031$ ), and docetaxel- or vinorelbine-based treatment showed a longer PFS compared to gemcitabine (9.4, 9.6, and 8.3 months, respectively, $P=0.033$ and $P=0.028$ ). Multivariate analysis indicated that the presence of an EGFR mutation was an independent predictive factor for PFS to first-line chemotherapy (95\% CI: $1.086-1.840, P=0.01)$.

Park et al $^{59}$ included 217 patients with advanced NSCLC who had received platinum doublet chemotherapy as a first-line regimen, with gemcitabine-based and taxane-based therapies administered in 131 (60.4\%) and 86 (39.6\%) cases, respectively. They found that taxane-based therapies had a higher DCR (71.8\% versus $88.5 \%, P=0.022)$ and longer PFS (5.7 versus 4.1 months, $P=0.002$ ) compared with gemcitabinebased treatment in patients with EGFR mutations, particularly in those with deletions in exon 19 (5.3 versus 3.7 months, $P=0.012$ ). The results suggested that an optimal cytotoxic chemotherapy regimen could be selected based on the $E G F R$ mutation status in patients with NSCLC.

However, the results of some research showed that there was no relationship between EGFR mutations and the response to cytotoxic chemotherapy. Lee et $\mathrm{al}^{60}$ investigated 90 patients, of whom 75 received platinum and 45 received paclitaxel as first-line chemotherapy agents. RR to firstline chemotherapy for patients with $E G F R$ mutations was $42.9 \%$, which was similar to that for wild-type $E G F R$ patients $(34.4 \%, P=0.55)$. Similarly, Takano et al ${ }^{61}$ reported that the RRs to first-line cytotoxic chemotherapy were not significantly different between EGFR mutation patients and $E G F R$ wild-type cases $(31.0 \%$ versus $28.0 \%$, respectively, $P=0.50)$.

In contrast, a chemosensitivity test performed by Yoshimasu et $\mathrm{al}^{62}$ demonstrated that the sensitivity to docetaxel was lower in lung cancers with EGFR mutations compared with in tumors with wild-type EGFR.

\section{Second-line treatment}

At present, international recommendations for second-line drugs in NSCLC patients are docetaxel, pemetrexed, and EGFR-TKIs. However, patients with EGFR mutations receiving EGFR-TKIs after progression on chemotherapy demonstrated a lower RR compared with those on first-line therapy. ${ }^{63-65}$ The Phase III Iressa NSCLC Trial Evaluating Response and Survival versus Taxotere (INTEREST) trial $^{66,67}$ compared the response to gefitinib and docetaxel as a second-line therapy in advanced NSCLC. The results showed that the RR to docetaxel was higher in patients with EGFR mutation-positive tumors compared with those with wild-type EGFR (21.1\% versus 9.8\%). Moreover, among patients who were treated with docetaxel, those with $E G F R$ mutations had a longer OS than wild-type patients, although there was no significant difference (16.6 versus 6.0 months, $P=0.59)$.

$\mathrm{Wu}$ et $\mathrm{al}^{68}$ analyzed 95 patients with stage IIIb or IV NSCLC after treatment with gefitinib as the first-line therapy who received a second-line treatment with a platinum-based or taxane-containing regimen. The results showed that the 
gemcitabine-plus-platinum regimen achieved better OS than erlotinib in patients with $E G F R$ mutations (27.1 versus 10 months, $P=0.035$ ) but not in patients with wild-type $E G F R$ (10.1 versus 12.7 months, $P=0.785$ ).

In the BR.21 trial, ${ }^{63,69}$ researchers compared erlotinib with a placebo in advanced NSCLC patients. Among the placebo subgroup, the data showed that patients with classical mutations had a longer median survival time than patients with EGFR wild-type or novel EGFR mutations (9.1, 3.5, and 3.5 months, respectively). However, there was no significant survival difference between EGFR classical or novel mutation patients and patients with wild-type EGFR (HR 0.65, 0.67 , and 0.73 , respectively).

As we can see from the results of the abovementioned studies, it has not been established whether EGFR mutations could predict the outcomes in NSCLC patients treated with cytotoxic chemotherapy. Regarding the results that showed that NSCLC patients with EGFR mutations achieved better therapeutic effect and longer survival time, one possible reason is that EGFR mutation patients have a favorable natural process, regardless of the efficacy of chemotherapy itself. Although a better outcome was found in mutation-positive NSCLC patients, this was not always obvious. Moreover, a majority of the previous related studies involved retrospective analysis and had a relatively small sample size, which could lead to some biases. Therefore, it is necessary to conduct further prospective studies to determine the predictive role of EGFR mutations for cytotoxic chemotherapy and the detailed prediction mechanism.

\section{Comparison of the response to chemotherapy or EGFR- TKIs between EGFR mutations in exon 19 and mutations in exon $2 \mathrm{I}$ in NSCLC}

In different types of $E G F R$ mutations, in-frame deletions in exon 19 and amino acid replacements in exon 21 (leucine to arginine at condon 858, p.L858R) were the most common mutations, and accounted for about $85 \%$ of all EGFR mutations in patients with NSCLC. ${ }^{70-72}$ The predictive and prognostic value in patients with $E G F R$ exon 19 mutation or with EGFR exon 21 mutation remains unclear (Table 3). In research performed by Cappuzzo et $\mathrm{al}^{73}$ EGFR mutation was detected in 24 patients, which included deletion in exon 19 in 15 cases and point mutation in exon 21 in seven cases. The authors found a $46.6 \%$ RR to chemotherapy in patients with EGFR deletions in exon 19 compared with $0 \% \mathrm{RR}$ in patients with other $E G F R$ mutations $(P=0.02)$, which suggested that patients with $E G F R$ exon 19 mutation might be more sensitive to EGFR-TKIs than patients with other EGFR mutations.

Jackman et $\mathrm{al}^{74}$ compared the clinical data and outcomes of patients whose tumors had an EGFR exon 19 mutation to those with EGFR exon 21 mutation in 36 NSCLC patients who were treated with gefitinib or erlotinib. The results indicated that patients with deletions in exon 19 (delp.729-761) had a significantly improved time to progression (24 versus 10 months, $P=0.04$ ) and $O S$ ( 38 versus 17 months, $P=0.0384$ ) than patients with a p.L858R mutation. Although there were no significant differences in multivariate analysis, patients with exon 19 mutation showed a higher RR than those with exon 21 mutation ( $73 \%$ versus $50 \%, P=0.25$ ).

Riely et $\mathrm{l}^{75}$ noted that patients with $E G F R$ exon 19 mutation had a longer median PFS (12 versus 5 months, $P=0.01$ ) and OS (34 versus 8 months, $P=0.01$ ) compared with those with EGFR exon 21 mutation after receiving EGFR-TKI treatment. Similar results were shown in a study by Rosell et al. $^{76}$ A pooled analysis of the LUX-Lung 3 and LUXLung 6 trials $^{77}$ indicated that the patients with deletions in exon 19 receiving first-line afatinib had a longer OS than those treated with standard chemotherapy (HR 0.59; 95\% CI: $0.45-0.77, P<0.001)$; however, in patients with p.L858R mutation, $\mathrm{HR}=1.25$ (95\% CI: $0.92-1.71, P=0.160)$. The results suggested that the patients with a particular $E G F R$ mutation (eg, deletion in exon 19) could acquire more obvious benefit from the first-line afatinib therapy.

In a study by Liu et $\mathrm{al}^{40}$ which enrolled 131 patients with completely resected lung adenocarcinoma, the results showed that, compared with the patients with exon 21 mutation, those with exon 19 mutation (delp.746-750) had longer DFS (46.2 versus 21.9 months, $P=0.056$ ) and 1-, $2-$, and 3 -year OS $(100 \%, 96.7 \%$, and $93.3 \%$, respectively, versus $91.3 \%, 82.6 \%$, and $60.9 \%$, respectively, $P=0.01$ ). However, several randomized Phase III studies reported no significant difference in PFS with EGFR-TKIs between the patients with deletions in exon 19 and those with exon 21 p.L858R mutation. ${ }^{52,78,79}$

Conversely, Shigematsu et $\mathrm{al}^{80}$ analyzed early-stage NSCLC patients who underwent resections and never received EGFR-TKIs. After comparing the outcomes of 31 cases with EGFR p.L858R and 31 cases with EGFR deletions in exon 19 (delp.729-761), they reported that patients with p.L858R attained a longer survival time $(P=0.05)$.

However, the study by Lee et $\mathrm{al}^{35}$ found that patients with exon 19 mutation recurred more frequently compared 


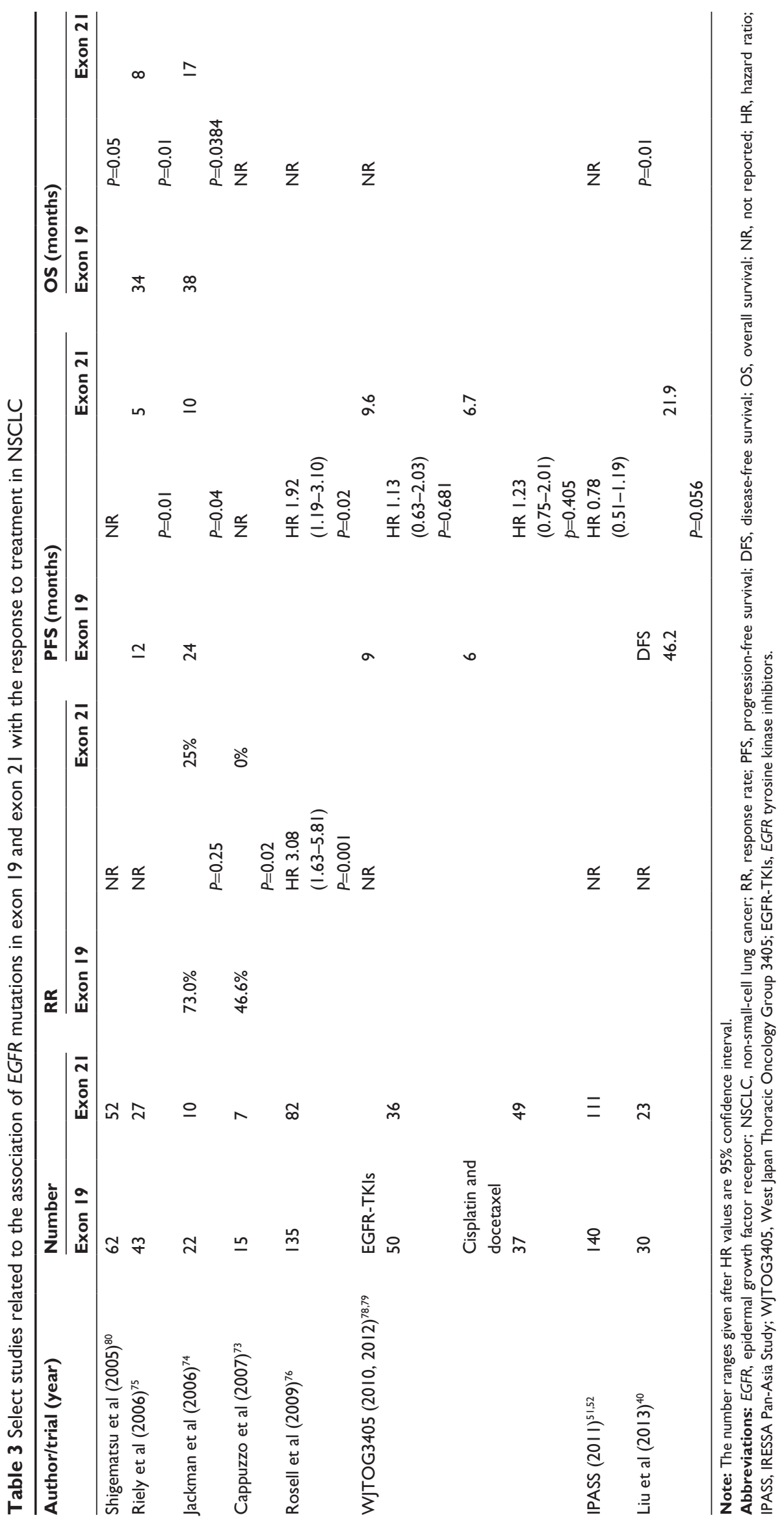


Table 4 Select studies related to T790M mutation as a prognostic marker for patients with NSCLC

\begin{tabular}{|c|c|c|c|c|c|c|c|c|c|}
\hline \multirow[t]{2}{*}{ Author/trial (year) } & \multirow[t]{2}{*}{ Number } & \multicolumn{2}{|c|}{$\begin{array}{l}\text { EGFR T790M mutation, } \\
\mathrm{n}\end{array}$} & \multicolumn{3}{|c|}{ PFS (months) } & \multicolumn{3}{|c|}{ OS (months) } \\
\hline & & Mutation & Wild-type & Mutation & & Wild-type & Mutation & & Wild-type \\
\hline \multirow[t]{2}{*}{ Oxnard et al $(20 \mathrm{II})^{91}$} & 93 & 58 (62.4\%) & 35 (37.6\%) & 19.0 & & 12.0 & 39.0 & & 26.0 \\
\hline & & & & & $P=0.036$ & & & $P=0.007$ & \\
\hline \multirow[t]{3}{*}{ Fujita et al $(2012)^{92}$} & 38 & 30 (78.9\%) & $8(21.1 \%)$ & TTF & & & & $N R$ & \\
\hline & & & & 9.0 & & 7.0 & & & \\
\hline & & & & & $P=0.44$ & & & & \\
\hline \multirow[t]{2}{*}{ Sun et al $(2013)^{95}$} & 70 & 36 (5I.4\%) & 34 (48.6\%) & 14.7 & & 14.1 & 43.5 & & 36.8 \\
\hline & & & & & $P=0.26$ & & & $P=0.23$ & \\
\hline \multirow[t]{2}{*}{ Kuiper et al $(2014)^{93}$} & 66 & 34 (51.5\%) & 32 (48.5\%) & 14.2 & & II.I & 45.9 & & 29.8 \\
\hline & & & & & $P=0.034$ & & & $P=0.213$ & \\
\hline \multirow[t]{6}{*}{ Li et al $(2014)^{94}$} & 54 & 29 (53.7\%) & 25 (46.3\%) & PFSI & & & & & \\
\hline & & & & 13.0 & & 10.5 & & & \\
\hline & & & & & $P=0.894$ & & & & \\
\hline & & & & PFS2 & & & OS2 & & \\
\hline & & & & 6.3 & & 2.6 & 39.8 & & 23.2 \\
\hline & & & & & $P=0.002$ & & & $P=0.044$ & \\
\hline
\end{tabular}

Abbreviations: EGFR, epidermal growth factor receptor; NSCLC, non-small-cell lung cancer; TTF, time to treatment failure; PFS, progression-free survival; PFSI, the time from the date of starting; PFS2, the time from the date of the first disease progression to the second disease progression; OS, overall survival; OS2, the time from the date of starting the therapy to death or last follow-up; NR, not reported.

with patients with exon 21 mutations (HR 4.13, 95\% CI: $1.14-14.88, P=0.03)$.

The results of several studies have suggested that the tumor biology of patients with different EGFR mutations is different, which indicates that specific types of $E G F R$ mutation may have an additional predictive role in NSCLC patients. The cause resulting in the different clinical outcomes between NSCLC patients with deletions in exon 19 and p.L858R point mutations remains unknown. One possible reason is that EGFR mutations in exon 19 are more sensitive to EGFR-TKIs or chemotherapy than exon 21 mutations. However, such differences also exist in patients who only receive surgical resection with lung cancer. In in vitro research, however, EGFR-TKIs had similar growth inhibitions to NSCLC cell lines with deletions in exon 19 or p.L858R mutations. ${ }^{21,81}$ There is a question about whether we should treat the two EGFR mutations equally when making clinical decisions. Prospective studies are needed to further investigate this difference.

\section{p.T790M mutation as a prognostic marker for patients with NSCLC}

Some mechanisms of acquired resistance to EGFR-TKIs have been identified, such as MET amplification, small-cell histologic transformation, and HER2 amplification. ${ }^{82-84}$ However, the p.T790M mutation is the most prevalent mechanism. p.T790M mutation was reported in $2.7 \%-40 \%$ of TKI-naïve patients. $^{20,85}$ Currently, almost all patients with activating mutations (deletion in exon 19 or point mutation in exon 21) eventually develop acquired resistance while receiving
EGFR-TKI therapy, ${ }^{20}$ and about $50 \%$ of these patients have a secondary mutation in exon 20 (p.T790M) ${ }^{86-90}$ The p.T790M mutation abolishes the influence of EGFR-TKIs by increasing the affinity for adenosine triphosphate (ATP). ${ }^{87}$ There is a major clinical problem in that NSCLC patients with EGFR mutations achieve acquired resistance after treatment with EGFR-TKIs.

Several studies have evaluated the predictive and prognostic role of p.T790M mutations in patients with NSCLC (Table 4). The results of the study by Oxnard et $\mathrm{al}^{91}$ showed that patients with p.T790M mutation at post-TKI biopsy had a longer post-progression survival compared with patients without p.T790M mutation after progression on EGFR-TKIs (19.0 versus 12.0 months, $P=0.036$ ). Moreover, those without p.T790M suffered a lower Karnofsky performance status at time of progression $(P=0.007)$.

In the research of Fujita et $\mathrm{al}^{92} 38$ EGFR-TKI-naïve patients with EGFR mutations who underwent curative pulmonary resection were included, and the EGFR p.T790M mutation at pre-TKI biopsy was detected in 30 patients (78.9\%). There was no significant difference in TTF between those with and without p.T790M mutation (9.0 versus 7.0 months, $P=0.44$ ) after receiving EGFR-TKIs. However, the authors divided the patients with p.T790M mutation mutation into strongly positive and modestly positive groups according to the frequency of positive signals, and revealed that the patients who were strongly positive had a longer TTF compared with those without p.T790M mutation $(P=0.0097)$ and those with modest positivity $(P=0.0019)$. This was the first report to reveal a positive relationship between the 
presence of p.T790M mutation before receiving EGFR-TKIs and prognosis of patients. The results suggested that the abundance rather than the presence of p.T790M mutation caused the benefits of EGFR-TKI treatment in NSCLC.

Kuiper et $\mathrm{al}^{93}$ analyzed the clinical data of 66 patients with EGFR mutations, and the results showed that patients with p.T790M mutation at post-TKI biopsy attained a longer PFS (14.2 versus 11.1 months, $P=0.034)$ and longer OS (45.9 versus 29.8 months, $P=0.213$ ) than those without p.T790M mutation on EGFR-TKI therapy.

Similar results were reported in a study by $\mathrm{Li}$ et al. ${ }^{94}$ p.T790M mutation was detected in 29 patients after the failure of EGFR-TKIs, and the authors found that the time from the date of starting EGFR-TKI treatment to disease progression or death (PFS1) was not influenced by p.T790M mutation (13.0 versus 10.5 months, $P=0.894$ ). However, among 41 patients treated with EGFR-TKIs beyond progression, the results showed that patients with p.T790M mutation had a longer time from the date of the first disease progression to the second disease progression (PFS2) (6.3 versus 2.6 months, $P=0.002$ ) and $O S$ (39.8 versus 23.2 months, $P=0.044$ ) than those with p.T790M wild-type. The data indicated that patients with p.T790M mutation after acquired resistance to EGFR-TKIs had better therapeutic effect to the continuous EGFR-TKI therapy. This conclusion requires further investigation.

In contrast, Sun et $\mathrm{al}^{95}$ analyzed 70 NSCLC patients who had acquired resistance to EGFR-TKIs and of whom 36 (51\%) had EGFR p.T790M mutation at post-TKI biopsy. No significant difference was found in post-progression survival (14.7 versus 14.1 months, $P=0.26$ ) and $\mathrm{OS}$ (43.5 versus 36.8 months, $P=0.23$ ) between patients with and without p.T790M mutation. Thirty-four patients were treated with subsequent afatinib after progression on EGFR-TKIs, and the patients with p.T790M mutation had a higher RR than those without p.T790M mutation ( $5 \%$ versus $38 \%, P=0.01$ ). However, the median PFS for afatinib was 3.2 months in the p.T790M mutation group and 4.6 months in the p.T790M wild-type group ( $P=0.33$ ).

A meta-analysis ${ }^{96}$ was performed to identify the role of EGFR p.T790M mutation in the prognosis of patients receiving EGFR-TKI therapy. The incidence of patients who had pretreatment p.T790M mutation ranged from $34.88 \%$ to $80.00 \%$. The authors found that patients with p.T790M mutation had a shorter PFS on EGFR-TKI treatment compared with p.T790M wild-type patients.

The studies above evaluated whether there was a prognostic value to the p.T790M mutation in NSCLC patients with EGFR mutations, but this remains unclear. Rather than finding a negative prognostic effect of p.T790M mutation with EGFR-TKI treatment, some research has indicated that the p.T790M mutation might have a positive prognostic value after progression on EGFR-TKIs. In a fundamental study, the existence of p.T790M mutation was correlated with a slow speed of tumor growth,${ }^{86}$ which may be the reason why patients with EGFR p.T790M mutation were usually found to have a longer survival time in clinical research. Knowledge of p.T790M mutation is essential for determining the optimal treatment for these patients and we expect that the p.T790M mutation will become the first acquired molecular marker with prognostic significance.

Some studies have demonstrated that there were activities against p.T790M mutation tumors in vitro and in vivo, ${ }^{97,98}$ and some clinical trials are ongoing. ${ }^{99,100}$ The results of CO-1686 indicated that three-quarters of patients with p.T790M mutation who progressed following EGFR-TKIs treatment could have PR in a Phase I trial. ${ }^{101}$ Preliminary data from a Phase I study in NSCLC patients with acquired resistance to EGFR-TKIs also showed that about one-half of the patients receiving AZD9291 treatment could achieve responses. ${ }^{100,102}$ Moreover, a Phase II trial suggested that the combination of cetuximab and afatinib had modest clinical activity in NSCLC patients with p.T790M mutation. ${ }^{103}$ However, there is still no standard therapy for patients with p.T790M mutation.

\section{First-line therapy in NSCLC patients with EGFR mutations}

Six randomized Phase III trials indicated that NSCLC patients with EGFR mutations receiving EGFR-TKIs as the first-line therapy could achieve higher RR and longer PFS than those receiving chemotherapy; however, no significant difference was found in OS between the two groups (Table 5). .1,51,78,79, 105- $^{-}$ 108,110,111 However, a pooled analysis of the LUX-Lung 3 and LUX-Lung 6 trials reported an improvement in OS in EGFR mutant patients receiving EGFR-TKIs in 2014. ${ }^{77}$

Among the subgroup of NSCLC patients with EGFR mutation, the results of IPASS ${ }^{51,52}$ indicated that the gefitinib arm had a higher RR $(71.2 \%$ versus $47.3 \%, P<0.001)$ and a longer PFS (9.5 versus 6.3 months, $P<0.001$ ) compared to the carboplatin/paclitaxel group, while no significant difference was found in OS between these two groups (21.6 versus 21.9 months, $P=0.990)$.

WJTOG (West Japan Thoracic Oncology Group) $3405^{78,79}$ was a Phase III study that analyzed the outcomes of 177 Japanese patients harboring EGFR mutations with advanced NSCLC. The researchers found that the patients who received gefitinib showed a significantly higher $\mathrm{RR}(62.1 \%$ versus $32.2 \%$, 


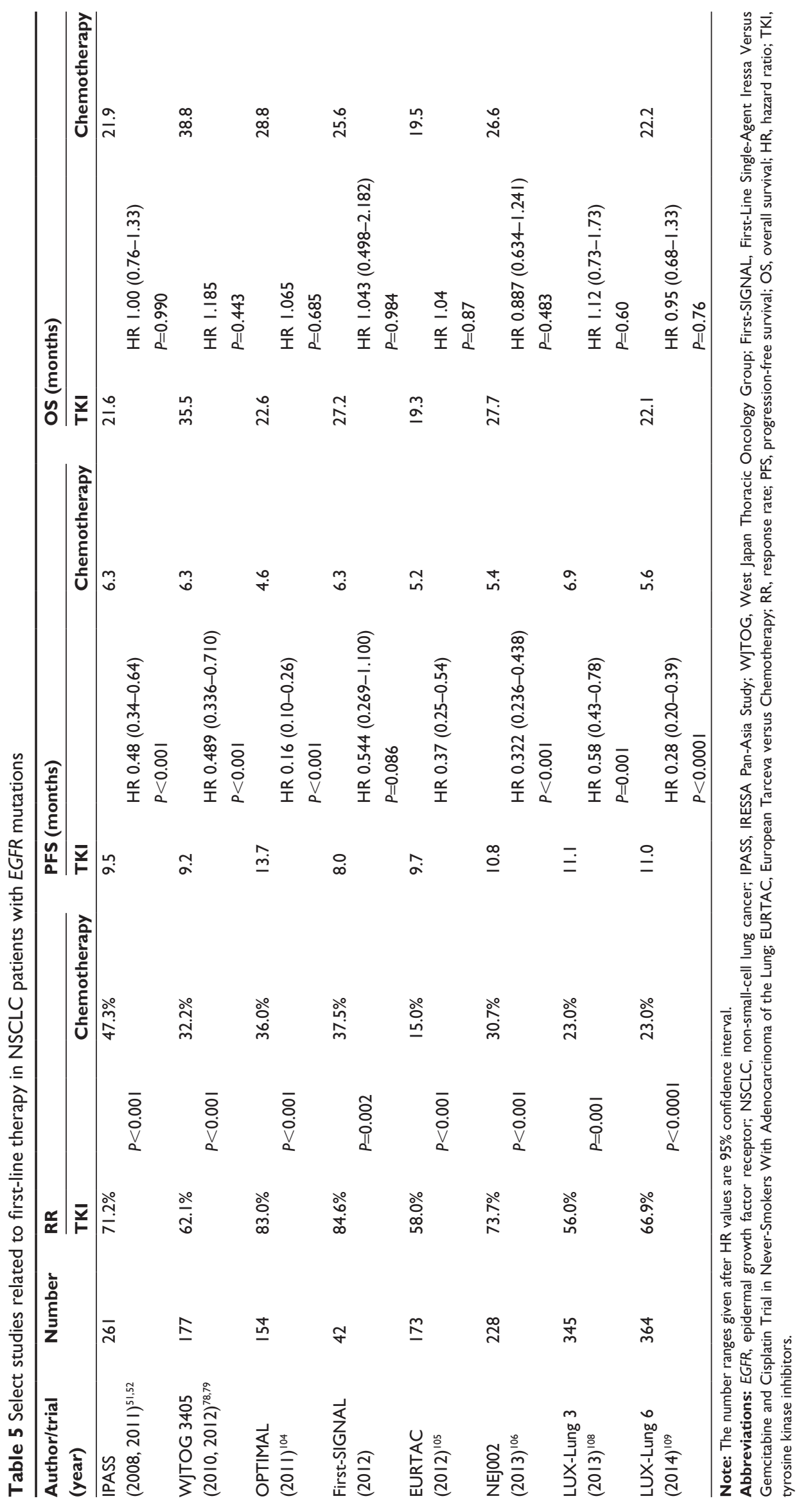


$P<0.001)$ and longer PFS (9.2 versus 6.3 months, $P<0.001)$ than those receiving cisplatin plus docetaxel.

The randomized Phase III First-Line Single-Agent Iressa Versus Gemcitabine and Cisplatin Trial in NeverSmokers With Adenocarcinoma of the Lung (First-SIGNAL) trial enrolled 313 Korean never-smokers with advanced lung adenocarcinoma. Ninety-six patients were evaluated for $E G F R$ mutation status and $E G F R$ mutation was detected in 42 patients. Of the patients who had EGFR mutation-positive tumors, the gefitinib group had a higher objective response rate (ORR) (84.6\% versus $37.5 \%, P=0.002)$ and a longer PFS ( 8.0 versus 6.3 months, $P=0.086$ ); however, the results failed to show a significant difference in OS. Similar results were shown in OPTIMAL study, ${ }^{104}$ European Tarceva versus Chemotherapy (EURTAC) study, ${ }^{105}$ and NEJ002 study. ${ }^{106}$

In 2013, a meta-analysis ${ }^{107}$ was performed to evaluate the favored therapy for first-line treatment in NSCLC patients with EGFR mutations. The results demonstrated that patients receiving EGFR-TKI therapy showed a higher RR (66.60\% versus $30.62 \%$, HR 5.68, 95\% CI: $3.17-10.18$, $P<0.001)$ and an improved PFS (9.5 versus 5.9 months, HR $0.37,95 \%$ CI: $0.27-0.52, P<0.001)$ compared with those receiving chemotherapy treatment. There was no significant difference in OS (30.5 versus 23.6 months, HR 0.94, 95\% CI: $0.77-1.15, P=0.57)$.

Recently, in two randomized Phase III trials, ${ }^{108,109}$ patients with EGFR mutations treated with second-generation EGFR-TKIs such as afatinib had better outcomes than those receiving chemotherapy (Table 5). The results of the LUXLung 3 study ${ }^{108}$ demonstrated that significantly improved $\mathrm{RR}$ and PFS were found with afatinib compared to chemotherapy in EGFR mutation patients (56\% versus $23 \%$, $P=0.001$ and 11.1 versus 6.9 months, $P=0.001$, respectively). Similar results were found in the LUX-Lung 6 trial. ${ }^{109}$ At the American Society of Clinical Oncology 2014 meeting, a pooled analysis of the LUX-Lung 3 and LUX-Lung 6 trials $^{77}$ provided new efficacy and safety data to support treatment with afatinib. The analysis included 631 advanced NSCLC patients with common EGFR mutations (deletions in exon 19 or p.L858R substitutions) and demonstrated that the patients attained longer OS when treated with first-line afatinib compared to standard chemotherapy (27.3 versus 24.3 months, HR $0.81,95 \%$ CI: $0.66-0.99, P=0.037$ ). This is the first time an actual survival benefit not seen in previous trials with gefitinib or erlotinib was shown.

The pooled analysis of the LUX-Lung 3 and LUX-Lung 6 trials $^{77}$ suggested that patients with EGFR mutations receiving EGFR-TKIs had a greater improvement in OS than those treated with chemotherapy, which provided the latest evidence toward determining whether EGFR-TKIs should be used as first- or second-line treatment. The results may influence the therapeutic regimen of the EGFR mutant patients in clinical practice. Afatinib is an irreversible inhibitor against p.T790M mutation and all EGFR family members. Although several related studies have been carried out, ${ }^{110-113}$ whether different EGFR-TKIs have different effects in $E G F R$-mutant patients is still unclear.

\section{Conclusion}

At present, EGFR mutation is the strongest predictive biomarker for the efficiency of EGFR-TKIs. ${ }^{14,115}$ Through analyzing relevant research of the past 20 years, we found that the prognostic and predictive value of EGFR mutation status in NSCLC remains uncertain, and it is difficult to understand the detailed mechanism by which cytotoxic agents influence $E G F R$-mutant and wild-type tumors differently. One study reported the differences in carcinogenic molecular genetic pathways between $E G F R$ mutation tumors and tumors with wild-type EGFR. ${ }^{116}$ The results showed that mutant EGFR selectively activated Akt and signal transducer and activator of transcription (STAT) signaling is related to cell survival; however, mutant $E G F R$ could not act on extracellular signal-regulated kinase signaling, the function of which is to induce proliferation. Wildtype $E G F R$ was proved to promote cellular proliferation and cell survival. Future molecular studies are needed to support this mechanism.

Although the majority of the selected research was performed retrospectively, and the studies achieved various conclusions, the results provide new information which can play an essential role in choosing the best treatment option for patients with NSCLC according to the EGFR mutation status. We believe that the presence of $E G F R$ mutations has an intrinsic relationship with the outcomes in patients with NSCLC. With improvements in technology for detecting gene mutations, some novel mutations in EGFR have been reported to be sensitive to TKIs, such as p.V765A, p.T783A, p.V774A, p.S784P, and p.V769A. ${ }^{117-121}$ The role of EGFR should be evaluated in more detail in prospectively designed research so that we can have a deeper understanding of the association of EGFR mutation with the curative effect and survival benefit of chemotherapy in the future.

\section{Disclosure}

The authors report no conflicts of interest in this work. 


\section{References}

1. Ferlay J, Shin HR, Bray F, Forman D, Mathers C, Parkin DM. Estimates of worldwide burden of cancer in 2008: GLOBOCAN 2008. Int J Cancer. 2010;127:2893-2917.

2. Le Péchoux C. Role of postoperative radiotherapy in resected nonsmall cell lung cancer: a reassessment based on new data. Oncologist. 2011;16:672-681.

3. Wu M, Zhao J, Song SW, et al. EGFR mutations are associated with prognosis but not with the response to front-line chemotherapy in the Chinese patients with advanced non-small cell lung cancer. Lung Cancer. 2010;67:343-347.

4. van Zandwijk N, Giaccone G. Treatment of metastatic non-small cell lung cancer. Curr Opin Oncol. 1996;8:120-125.

5. Piyathilake CJ, Frost AR, Manne U, et al. Differential expression of growth factors in squamous cell carcinoma and precancerous lesions of the lung. Clin Cancer Res. 2002;8:734-744.

6. Port JL, Kent MS, Korst RJ, Libby D, Pasmantier M, Altorki NK. Tumor size predicts survival within stage IA non-small cell lung cancer. Chest. 2003;124:1828-1833.

7. Nicholson RI, Gee JM, Harper ME. EGFR and cancer prognosis. Eur J Cancer. 2001;37 Suppl 4:S9-S15.

8. Onn A, Correa AM, Gilcrease M, et al. Synchronous overexpression of epidermal growth factor receptor and HER2-neu protein is a predictor of poor outcome in patients with stage I non-small cell lung cancer. Clin Cancer Res. 2004;10:136-143.

9. Lonardo F, Dragnev KH, Freemantle SJ, et al. Evidence for the epidermal growth factor receptor as a target for lung cancer prevention. Clin Cancer Res. 2002;8:54-60.

10. Larsen AK, Ouaret D, El Ouadrani K, Petitprez A. Targeting EGFR and $\operatorname{VEGF}(\mathrm{R})$ pathway cross-talk in tumor survival and angiogenesis. Pharmacol Ther. 2011;131:80-90.

11. Lichtenberger BM, Tan PK, Niederleithner H, Ferrara N, Petzelbauer P, Sibilia M. Autocrine VEGF signaling synergizes with EGFR in tumor cells to promote epithelial cancer development. Cell. 2010;140: 268-279.

12. Yatabe Y, Takahashi T, Mitsudomi T. Epidermal growth factor receptor gene amplification is acquired in association with tumor progression of EGFR-mutated lung cancer. Cancer Res. 2008;68:2106-2111.

13. Barr S, Thomson S, Buck E, et al. Bypassing cellular EGF receptor dependence through epithelial-to-mesenchymal-like transitions. Clin Exp Metastasis. 2008;25:685-693.

14. Gazdar AF, Shigematsu H, Herz J, Minna JD. Mutations and addiction to EGFR: the Achilles 'heal' of lung cancers? Trends Mol Med. 2004; 10:481-486.

15. Pao W, Miller VA. Epidermal growth factor receptor mutations, smallmolecule kinase inhibitors, and non-small-cell lung cancer: current knowledge and future directions. J Clin Oncol. 2005;23:2556-2568.

16. Haneda H, Sasaki H, Lindeman N, et al. A correlation between EGFR gene mutation status and bronchioloalveolar carcinoma features in Japanese patients with adenocarcinoma. Jpn J Clin Oncol. 2006;36:69-75.

17. Choi YH, Lee JK, Kang HJ, et al. Association between age at diagnosis and the presence of EGFR mutations in female patients with resected non-small cell lung cancer. J Thorac Oncol. 2010;5:1949-1952.

18. Laack E, Simon R, Regier M, et al. Miliary never-smoking adenocarcinoma of the lung: strong association with epidermal growth factor receptor exon 19 deletion. J Thorac Oncol. 2011;6:199-202.

19. Lynch TJ, Bell DW, Sordella R, et al. Activating mutations in the epidermal growth factor receptor underlying responsiveness of non-small-cell lung cancer to gefitinib. $N$ Engl J Med. 2004;350:2129-2139.

20. Mok TS, Wu YL, Thongprasert S, et al. Gefitinib or carboplatin-paclitaxel in pulmonary adenocarcinoma. $N$ Engl J Med. 2009;361:947-957.

21. Paez JG, Jänne PA, Lee JC, et al. EGFR mutations in lung cancer: correlation with clinical response to gefitinib therapy. Science. 2004;304:1497-1500

22. Cappuzzo F, Hirsch FR, Rossi E, et al. Epidermal growth factor receptor gene and protein and gefitinib sensitivity in non-small-cell lung cancer. J Natl Cancer Inst. 2005;97:643-655.
23. Pao W, Miller V, Zakowski M, et al. EGF receptor gene mutations are common in lung cancer from "never-smokers" and are associated with sensitivity of tumors to gefitinib and erlotinib. Proc Natl Acad Sci USA. 2004;101:13306-13311.

24. Hirsch FR, Varella-Garcia M, McCoy J, et al; Southwest Oncology Group. Increased epidermal growth factor receptor gene copy number detected by fluorescence in situ hybridization associates with increased sensitivity to gefitinib in patients with bronchioloalveolar carcinoma subtypes: a Southwest Oncology Group Study. J Clin Oncol. 2005;23:6838-6845.

25. Hirsch FR, Varella-Garcia M, Bunn PA, et al. Molecular predictors of outcome with gefitinib in a phase III placebo-controlled study in advanced non-small-cell lung cancer. J Clin Oncol. 2006;24: 5034-5042.

26. Giaccone G, Herbst RS, Manegold C, et al. Gefitinib in combination with gemcitabine and cisplatin in advanced non-small-cell lung cancer: a phase III trial - INTACT 1. J Clin Oncol. 2004;22: 777-784.

27. Gatzemeier U, Pluzanska A, Szczesna A, et al. Phase III study of erlotinib in combination with cisplatin and gemcitabine in advanced non-small-cell lung cancer: the Tarceva Lung Cancer Investigation Trial. J Clin Oncol. 2007;25:1545-1552.

28. Eisenhauer EA, Therasse P, Bogaerts J, et al. New response evaluation criteria in solid tumours: revised RECIST guideline (version 1.1). Eur $J$ Cancer. 2009;45:228-247.

29. al-Kattan K, Sepsas E, Fountain SW, Townsend ER. Disease recurrence after resection for stage I lung cancer. Eur J Cardiothorac Surg. 1997;12:380-384.

30. Martin J, Ginsberg RJ, Venkatraman ES, et al. Long-term results of combined-modality therapy in resectable non-small-cell lung cancer. J Clin Oncol. 2002;20:1989-1995.

31. Martini N, Bains MS, Burt ME, et al. Incidence of local recurrence and second primary tumors in resected stage I lung cancer. J Thorac Cardiovasc Surg. 1995;109:120-129.

32. Jemal A, Siegel R, Ward E, et al. Cancer statistics, 2008. CA Cancer J Clin. 2008;58:71-96.

33. Wang CL, Yue DS, Zhang ZF, et al. [Treatment and prognostic analysis of 1638 patients with non-small cell lung cancer]. Zhonghua Wai Ke Za Zhi. 2011;49:618-622. Chinese.

34. Li Z, Yu Y, Lu J, et al. Analysis of the T descriptors and other prognosis factors in pathologic stage I non-small cell lung cancer in China. J Thorac Oncol. 2009;4:702-709.

35. Lee YJ, Park IK, Park MS, et al. Activating mutations within the EGFR kinase domain: a molecular predictor of disease-free survival in resected pulmonary adenocarcinoma. J Cancer Res Clin Oncol. 2009;135:1647-1654.

36. Jeon JH, Kang CH, Kim HS, Seong YW, Park IK, Kim YT. Prognostic and predictive role of epidermal growth factor receptor mutation in recurrent pulmonary adenocarcinoma after curative resection. Eur J Cardiothorac Surg. Epub 2014 Apr 22.

37. Sasaki H, Shimizu S, Endo K, et al. EGFR and erbB2 mutation status in Japanese lung cancer patients. Int J Cancer. 2006;118: 180-184.

38. Kosaka T, Yatabe Y, Onozato R, Kuwano H, Mitsudomi T. Prognostic implication of EGFR, KRAS, and TP53 gene mutations in a large cohort of Japanese patients with surgically treated lung adenocarcinoma. J Thorac Oncol. 2009;4:22-29.

39. D'Angelo SP, Janjigian YY, Ahye N, et al. Distinct clinical course of EGFR-mutant resected lung cancers: results of testing of 1,118 surgical specimens and effects of adjuvant gefitinib and erlotinib. J Thorac Oncol. 2012;7:1815-1822.

40. Liu WS, Zhao LJ, Pang QS, et al. Prognostic value of epidermal growth factor receptor mutations in resected lung adenocarcinomas. Med Oncol. 2014;31:771.

41. Kobayashi N, Toyooka S, Ichimura K, et al. Non-BAC component but not epidermal growth factor receptor gene mutation is associated with poor outcomes in small adenocarcinoma of the lung. J Thorac Oncol. 2008;3:704-710. 
42. Kosaka T, Yatabe Y, Endoh H, Kuwano H, Takahashi T, Mitsudomi T. Mutations of the epidermal growth factor receptor gene in lung cancer: biological and clinical implications. Cancer Res. 2004;64: 8919-8923.

43. Lim KH, Huang MJ, Liu HC, Kuo HT, Tzen CY, Hsieh RK. Lack of prognostic value of EGFR mutations in primary resected non-small cell lung cancer. Med Oncol. 2007;24:388-393.

44. Nose N, Sugio K, Oyama T, et al. Association between estrogen receptor-beta expression and epidermal growth factor receptor mutation in the postoperative prognosis of adenocarcinoma of the lung. J Clin Oncol. 2009;27:411-417.

45. Marks JL, Broderick S, Zhou Q, et al. Prognostic and therapeutic implications of EGFR and KRAS mutations in resected lung adenocarcinoma. $J$ Thorac Oncol. 2008;3:111-116.

46. Pfister DG, Johnson DH, Azzoli CG, et al; American Society of Clinical Oncology. American Society of Clinical Oncology treatment of unresectable non-small-cell lung cancer guideline: update 2003. J Clin Oncol. 2004;22:330-353.

47. Schiller JH, Harrington D, Belani CP, et al; Eastern Cooperative Oncology Group. Comparison of four chemotherapy regimens for advanced non-small-cell lung cancer. $N$ Engl J Med. 2002;346:92-98.

48. Fossella F, Pereira JR, von Pawel J, et al. Randomized, multinational, phase III study of docetaxel plus platinum combinations versus vinorelbine plus cisplatin for advanced non-small-cell lung cancer: the TAX 326 study group. J Clin Oncol. 2003;21:3016-3024.

49. Scagliotti GV, De Marinis F, Rinaldi M, et al; Italian Lung Cancer Project. Phase III randomized trial comparing three platinum-based doublets in advanced non-small-cell lung cancer. J Clin Oncol. 2002;20 4285-4291.

50. Kelly K, Crowley J, Bunn PA Jr, et al. Randomized phase III trial of paclitaxel plus carboplatin versus vinorelbine plus cisplatin in the treatment of patients with advanced non - small-cell lung cancer: a Southwest Oncology Group trial. J Clin Oncol. 2001;19:3210-3218.

51. Mok T, Wu YL, Thongprasert S, et al. Phase III, randomized, open-label, first-line study of gefitinib versus carboplatin/paclitaxel in clinically selected patients with advanced non-small-cell lung cancer (IPASS). Ann Oncol. 2008;19(Suppl 8)(viiil, Abstract LBA2).

52. Fukoka M, Wu YL, Thongprasert S, et al. Biomarker analyses and final overall survival results from a phase III, randomized, open-label, first-line study of gefitinib versus carboplatin/paclitaxel in clinically selected patients with advanced non-small-cell lung cancer in Asia (IPASS). J Clin Oncol. 2011;29:2866-2874.

53. Han JY, Par K, Sim SW, et al. First-SIGNAL: first-line single-agent iressa versus gemcitabine and cisplatin trial in never-smokers with adenocarcinoma of the lung. $J$ Clin Oncol. 2012;30:1122-1128.

54. Bell DW, Lynch TJ, Haserlat SM, et al. Epidermal growth factor receptor mutations and gene amplification in non-small-cell lung cancer: molecular analysis of the IDEAL/INTACT gefitinib trials. J Clin Oncol. 2005;23:8081-8092

55. Eberhard DA, Johnson BE, Amler LC, et al. Mutations in the epidermal growth factor receptor and in KRAS are predictive and prognostic indicators in patients with non-small-cell lung cancer treated with chemotherapy alone and in combination with erlotinib. J Clin Oncol. 2005;23:5900-5909.

56. Hotta K, Kiura K, Toyooka S, et al. Clinical significance of epidermal growth factor receptor gene mutations on treatment outcome after firstline cytotoxic chemotherapy in Japanese patients with non-small cell lung cancer. J Thorac Oncol. 2007;2:632-637.

57. Kalikaki A, Koutsopoulos A, Hatzidaki D, et al. Clinical outcome of patients with non-small cell lung cancer receiving front-line chemotherapy according to EGFR and K-RAS mutation status. Lung Cancer. 2010;69:110-115.

58. Dong X, Zhao X, Hao Y, Wei Y, Yin Q, Du J. Response to first-line chemotherapy in patients with non-small-cell lung cancer according to epidermal growth factor receptor and K-RAS mutation status. Clin Lung Cancer. 2013;14:680-687.

59. Park JH, Lee SH, Keam B, et al. EGFR mutations as a predictive marker of cytotoxic chemotherapy. Lung Cancer. 2012;77:433-437.
60. Lee KH, Han SW, Hwang PG, et al. Epidermal growth factor receptor mutations and response to chemotherapy in patients with non-small-cell lung cancer. Jpn J Clin Oncol. 2006;36:334-350.

61. Takano T, Fukui T, Ohe Y, et al. EGFR mutations predict survival benefit from gefitinib in patients with advanced lung adenocarcinoma: a historical comparison of patients treated before and after gefitinib approval in Japan. J Clin Oncol. 2008;26:5589-5595.

62. Yoshimasu T, Oura S, Ohta F, et al. Epidermal growth factor receptor mutations are associated with docetaxel sensitivity in lung cancer. J Thorac Oncol. 2011;6:1658-1662.

63. Tsao MS, Sakurada A, Cutz JC, et al. Erlotinib in lung cancer molecular and clinical predictors of outcome. N Engl J Med. 2005;353: $133-144$.

64. Maemondo M, Inoue A, Kobayashi K, et al; North-East Japan Study Group. Gefitinib or chemotherapy for non-small-cell lung cancer with mutated EGFR. N Engl J Med. 2010;362:2380-2388.

65. Sugio K, Uramoto H, Onitsuka T, et al. Prospective phase II study of gefitinib in non-small cell lung cancer with epidermal growth factor receptor gene mutations. Lung Cancer. 2009;64:314-318.

66. Kim ES, Hirsh V, Mok T, et al. Gefitinib versus docetaxel in previously treated non-small-cell lung cancer (INTEREST): a randomised phase III trial. Lancet. 2008;372:1809-1818.

67. Douillard JY, Shepherd FA, Hirsh V, et al. Molecular predictors of outcome with gefitinib and docetaxel in previously treated non-smallcell lung cancer: data from the randomized phase III INTEREST trial. J Clin Oncol. 2010;28:744-752.

68. Wu JY, Shih JY, Yang CH, et al. Second-line treatments after first-line gefitinib therapy in advanced nonsmall cell lung cancer. Int J Cancer. 2010;126:247-255.

69. Shepherd FA, Tsao MS. Unraveling the mystery of prognostic and predictive factors in epidermal growth factor receptor therapy. J Clin Oncol. 2006;24:1219-1220.

70. Gazdar AF. Activating and resistance mutations of EGFR in non-smallcell lung cancer: role in clinical response to EGFR tyrosine kinase inhibitors. Oncogene. 2009;28 Suppl 1:S24-S31.

71. Sharma SV, Bell DW, Settleman J, Haber DA. Epidermal growth factor receptor mutations in lung cancer. Nat Rev Cancer. 2007;7:169-181.

72. Chintala L, Kurzrock R. Epidermal growth factor receptor mutation and diverse tumors: case report and concise literature review. Mol Oncol. 2010;4:306-308.

73. Cappuzzo F, Ligorio C, Toschi L, et al. EGFR and HER2 gene copy number and response to first-line chemotherapy in patients with advanced non-small cell lung cancer (NSCLC). J Thorac Oncol. 2007;2: 423-429.

74. Jackman DM, Yeap BY, Sequist LV, et al. Exon 19 deletion mutations of epidermal growth factor receptor are associated with prolonged survival in non-small cell lung cancer patients treated with gefitinib or erlotinib. Clin Cancer Res. 2006;12:3908-3914.

75. Riely GJ, Pao W, Pham DK, et al. Clinical course of patients with nonsmall cell lung cancer and epidermal growth factor receptor exon 19 and exon 21 mutations treated with gefitinib or erlotinib. Clin Cancer Res. 2006;12:839-844.

76. Rosell R, Moran T, Queralt C, et al; Spanish Lung Cancer Group. Screening for epidermal growth factor receptor mutations in lung cancer N Engl J Med. 2009;361:958-967.

77. Yang J, Sequist L, Schuler M, et al. Overall survival (OS) in patients with advanced non-small cell lung cancer (NSCLC) harbouring common (Del19/L858R) epidermal growth factor receptor mutations (EGFR mut): pooled analysis of two large open-label phase III studies (LUX-Lung 3 [LL3] and LUX-Lung 6 [LL6] comparing afatinib with chemotherapy. Abstract \#8004. Presented at: 2014 American Society of Clinical Oncology, 50th Annual Meeting; May 30-June 3, 2014; Chicago, IL

78. Mitsudomi T, Morita S, Yatabe Y, et al; West Japan Oncology Group. Gefitinib versus cisplatin plus docetaxel in patients with non-small-cell lung cancer harboring mutations of epidermal growth factor receptor (WJTOG3405): an open label, randomized phase 3 trial. Lancet Oncol. 2010;11:121-128. 
79. Mitsudomi T, Morita S, Yatabe Y, et al. Updated overall survival results of WJTOG 3405, a randomized phase III trial comparing gefitinib (G) with cisplatin plus docetaxel (CD) as the first-line treatment for patients with non-small cell lung cancer harboring mutations of the epidermal growth factor receptor (EGFR). J Clin Oncol. 2012;30(suppl; abstr 7521).

80. Shigematsu H, Lin L, Takahashi T, et al. Clinical and biological features associated with epidermal growth factor receptor gene mutations in lung cancers. J Natl Cancer Inst. 2005;97:339-346.

81. Mukohara T, Engelman JA, Hanna NH, et al. Differential effects of gefitinib and cetuximab on non-small-cell lung cancers bearing epidermal growth factor receptor mutations. J Natl Cancer Inst. 2005;97: 1185-1194.

82. Bean J, Brennan C, Shih JY, et al. MET amplification occurs with or without T790M mutations in EGFR mutant lung tumors with acquired resistance to gefitinib or erlotinib. Proc Natl Acad Sci US A. 2007;104: 20932-20937.

83. Sequist LV, Waltman BA, Dias-Santagata D, et al. Genotypic and histological evolution of lung cancers acquiring resistance to EGFR inhibitors. Sci Transl Med. 2011;3:75ra26.

84. Chmielecki J, Foo J, Oxnard GR, et al. Optimization of dosing for EGFR-mutant non-small cell lung cancer with evolutionary cancer modeling. Sci Transl Med. 2011;3(90):90ra59.

85. Rosell R, Molina MA, Costa C, et al. Pretreatment EGFR T790M mutation and BRCA1 mRNA expression in erlotinib-treated advanced non-small-cell lung cancer patients with EGFR mutations. Clin Cancer Res. 2011;17:1160-1168.

86. Chmielecki J, Foo J, Oxnard GR, et al. Optimization of dosing for EGFR-mutant non-small cell lung cancer with evolutionary cancer modeling. Sci Transl Med. 2011;3:90ra59.

87. Yun CH, Mengwasser KE, Toms AV, et al. The T790M mutation in EGFR kinase causes drug resistance by increasing the affinity for ATP. Proc Natl Acad Sci U S A. 2008;105:2070-2075.

88. Kobayashi S, Boggon TJ, Dayaram T, et al. EGFR mutation and resistance of non-small-cell lung cancer to gefitinib. N Engl J Med. 2005; 352:786-792.

89. Pao W, Miller VA, Politi KA, et al. Acquired resistance of lung adenocarcinomas to gefitinib or erlotinib is associated with a second mutation in the EGFR kinase domain. PLoS Med. 2005;2:e73.

90. Yu HA, Arcila ME, Rekhtman N, et al. Analysis of tumor specimens at the time of acquired resistance to EGFR-TKI therapy in 155 patients with EGFR-mutant lung cancers. Clin Cancer Res. 2013;19: 2240-2247.

91. Oxnard GR, Arcila ME, Sima CS, et al. Acquired resistance to EGFR tyrosine kinase inhibitors in EGFR-mutant lung cancer: distinct natural history of patients with tumors harboring the T790M mutation. Clin Cancer Res. 2011;17:1616-1622.

92. Fujita Y, Suda K, Kimura H, et al. Highly sensitive detection of EGFR T790M mutation using colony hybridization predicts favorable prognosis of patients with lung cancer harboring activating EGFR mutation. $J$ Thorac Oncol. 2012;7:1640-1644.

93. Kuiper JL, Heideman DA, Thunnissen E, et al. Incidence of T790M mutation in (sequential) rebiopsies in EGFR-mutated NSCLC-patients. Lung Cancer. 2014;85:19-24.

94. Li W, Ren S, Li J, et al. T790M mutation is associated with better efficacy of treatment beyond progression with EGFR-TKI in advanced NSCLC patients. Lung Cancer. 2014;84:295-300.

95. Sun JM, Ahn MJ, Choi YL, Ahn JS, Park K. Clinical implications of T790M mutation in patients with acquired resistance to EGFR tyrosine kinase inhibitors. Lung Cancer. 2013;82:294-298.

96. Ding D, Yu Y, Li Z, Niu X, Lu S. The predictive role of pretreatment epidermal growth factor receptor T790M mutation on the progression-free survival of tyrosine-kinase inhibitor-treated non-small cell lung cancer patients: a meta-analysis. Onco Targets Ther. 2014;7: 387-393.

97. Walter AO, Tjin R, Haringsma H, et al. CO-1686, an orally available, mutant-selective inhibitor of the epidermal growth factor receptor $(E G F R)$ causes tumor shrinkage in non-small cell lung cancer (NSCLC) with T790M mutations. Mol Cancer Ther. 2011; 11(Suppl 1):C189.
98. Zhou W, Ercan D, Chen L, et al. Novel mutant-selective EGFR kinase inhibitors against EGFR T790M. Nature. 2009;462:1070-1074.

99. Clovis Oncology, Inc. Study to Evaluate Safety, Pharmacokinetics, and Efficacy of CO-1686 in Previously Treated Mutant Epidermal Growth Factor Receptor (EGFR) in Non-Small Cell Lung Cancer (NSCLC) Patients. Available from: http://www.clinicaltrials.gov/ show/NCT01526928. NLM identifier: NCT01526928. Accessed April 13, 2013.

100. Ranson M, Pao W, Kim D, et al. An irreversible, potent and selective tyrosine kinase inhibitor (TKI) of activating (EGFRM+) and resistance (T790M) mutations in advanced NSCLC. J Thorac Oncol. 2014;8(Suppl 2):S389.

101. Sequist LV, Soria JC, Gadgeel SM, et al. First-in-human evaluation of CO-1686, an irreversible, selective, and potent tyrosine kinase inhibitor of EGFR T790M. J Clin Oncol. 2013;31;(Suppl 31; abstr 2524).

102. Ranson M, Pao W, Kim D, et al. Preliminary results from a Phase I study with AZD9291: An irreversible inhibitor of epidermal growth factor receptor (EGFR) activating and resistance mutations in non-small-cell lung cancer (NSCLC). Eur J Cancer. 2013;49(Suppl 3):S15.

103. Janjigian YY, Smit EF, Groen HJ, et al. Dual inhibition of EGFR with afatinib and cetuximab in kinase inhibitor-resistant EGFR-mutant lung cancer with and without T790M mutations. Cancer Discov. 2014;4:1036-1045.

104. Zhou C, Wu YL, Chen G, et al. Erlotinib versus chemotherapy as first-line treatment for patients with advanced EGFR mutationpositive non-small-cell lung cancer (OPTIMAL, CTONG-0802): a multicenter, open-label, randomized, phase 3 study. Lancet Oncol. 2011;12:735-742.

105. Rosell R, Carcereny E, Gervais R, et al; Spanish Lung Cancer Group in collaboration with Groupe Français de Pneumo-Cancérologie and Associazione Italiana Oncologia Toracica. Erlotinib versus standard chemotherapy as first-line treatment for European patients with advanced EGFR mutation-positive non-small-cell lung cancer (EURTAC): a multicentre, open-label, randomised phase 3 trial. Lancet Oncol. 2012;13:239-246.

106. Inoue A, Kobayashi K, Maemondo M, et al; North-East Japan Study Group. Updated overall survival results from a randomized phase III trial comparing gefitinib with carboplatin-paclitaxel for chemo-naïve non-small cell lung cancer with sensitive EGFR gene mutations (NEJ002). Ann Oncol. 2013;24:54-59.

107. Gao G, Ren S, Li A, et al. Epidermal growth factor receptortyrosine kinase inhibitor therapy is effective as first-line treatment of advanced non-small-cell lung cancer with mutated EGFR: a metaanalysis from six phase III randomized controlled trials. Int $J$ Cancer. 2012;131:E822-E829.

108. Sequist LV, Yang JC, Yamamoto N, et al. Phase III study of afatinib or cisplatin plus pemetrexed in patients with metastatic lung adenocarcinoma with EGFR mutations. J Clin Oncol. 2013;31:3327-3334.

109. Wu YL, Zhou C, Hu CP, et al. Afatinib versus cisplatin plus gemcitabine for first-line treatment of Asian patients with advanced non-small-cell lung cancer harbouring EGFR mutations (LUX-Lung 6): an open-label, randomised phase 3 trial. Lancet Oncol. 2014;15:213-222.

110. Paz-Ares L, Soulières D, Klughammer B, Bara I, Moecks J, Mok T. Pooled analysis of clinical outcomes for patients with EGFR mutations in non-small cell lung cancer: an update. Ann Oncol. 2012;23 (Suppl 9, abstract 1254P).

111. Petrelli F, Borgonovo K, Cabiddu M, Barni S. Efficacy of EGFR tyrosine kinase inhibitors in patients with EGFR-mutated non-smallcell lung cancer: a meta-analysis of 13 randomized trials. Clin Lung Cancer. 2012;13:107-114.

112. Liang W, Wu X, Fang W, et al. Network meta-analysis of erlotinib, gefitinib, afatinib and icotinib in patients with advanced non-smallcell lung cancer harboring EGFR mutations. PLoS One. 2014;9: e85245.

113. Kris MG, Mok T, Ignatius SH, et al. First-line dacomitinib (PF-00299804), an irreversible pan-HER tyrosine kinase inhibitor, for patients with EGFR-mutant lung cancers. J Clin Oncol. 2012;30 (suppl; abstr 7530). 
114. Lara-Guerra H, Waddell TK, Salvarrey MA, et al. Phase II study of preoperative gefitinib in clinical stage I non-small-cell lung cancer. J Clin Oncol. 2009;27:6229-6236.

115. Roberts PJ, Stinchcombe TE, Der CJ, Socinski MA. Personalized medicine in non-small-cell lung cancer: is KRAS a useful marker in selecting patients for epidermal growth factor receptor-targeted therapy? J Clin Oncol. 2010;28:4769-4777.

116. Sordella R, Bell DW, Haber DA, Settleman J. Gefitinib-sensitizing EGFR mutations in lung cancer activate anti-apoptotic pathways. Science. 2004;305:1163-1167.

117. Chou TY, Chiu CH, Li LH, et al. Mutation in the tyrosine kinase domain of epidermal growth factor receptor is a predictive and prognostic factor for gefitinib treatment in patients with non-small cell lung cancer. Clin Cancer Res. 2005;11:3750-3757.
118. Wu JY, Yu CJ, Chang YC, Yang CH, Shih JY, Yang PC. Effectiveness of tyrosine kinase inhibitors on "uncommon" epidermal growth factor receptor mutations of unknown clinical significance in non-small cell lung cancer. Clin Cancer Res. 2011;17:3812-3821.

119. Xu JM, Han Y, Duan HQ, et al. EGFR mutations and HER2/3 protein expression and clinical outcome in Chinese advanced non-small cell lung cancer patients treated with gefitinib. J Cancer Res Clin Oncol. 2009;135:771-782.

120. Xing K, Zhou X, Zhao X, et al. A novel point mutation in exon 20 of EGFR showed sensitivity to erlotinib. Med Oncol. 2014;31:36.

121. Berge EM, Aisner DL, Doebele RC. Erlotinib response in an NSCLC patient with a novel compound G719D+L861R mutation in EGFR. J Thorac Oncol. 2013;8:e83-e84.

\section{Publish your work in this journal}

Drug Design, Development and Therapy is an international, peerreviewed open-access journal that spans the spectrum of drug design and development through to clinical applications. Clinical outcomes, patient safety, and programs for the development and effective, safe, and sustained use of medicines are a feature of the journal, which has also been accepted for indexing on PubMed Central. The manuscript management system is completely online and includes a very quick and fair peer-review system, which is all easy to use. Visit http://www.dovepress.com/testimonials.php to read real quotes from published authors.

Submit your manuscript here: http://www.dovepress.com/drug-design-development-and-therapy-journal 